\title{
An Integrated Approach to Biases in Referent-Specific Judgments
}

\author{
Andrew R. Smith ${ }^{\mathrm{a} *}$, Paul D. Windschitl ${ }^{\mathrm{b}}$ and Jason P. Rose ${ }^{\mathrm{c}}$ \\ ${ }^{a}$ Department of Psychology, Appalachian State University, Boone, North Carolina, USA; \\ University, City, Country; ${ }^{b}$ Department of Psychological \& Brain Sciences, University of \\ Iowa, Iowa City, Iowa, USA; ' University of Toledo, Toledo, Ohio, USA
}

Correspondence concerning this article should be addressed to Andrew R. Smith (smithar3@appstate.edu) or Paul D. Windschitl (paul-windschitl@uiowa.edu).

This project was supported by a research grant (SES 09-61252) to Paul D. Windschitl from the National Science Foundation. 


\section{An Integrated Approach to Biases in Referent-Specific Judgments}

This paper focuses on what we call referent-specific judgments (i.e., judgments that require specific comparisons). They can have many forms-including comparative judgments, probability judgments, proportion estimates, and ranks—but the different forms seem vulnerable to similar biases. We present a Referent-Specific Judgment Framework (RSJF) aimed at providing a more organized understanding of these biases and the explanations that have been proposed for them across distinct literatures. Two studies tested predictions of RSJF as they apply to similarities and differences in bias among comparative and probability judgments that qualify as referent-specific judgments. The results revealed the expected similarities and differences, and they more generally supported the utility of theorizing about referent-specific judgments as a coherent class of judgments.

Keywords: comparative judgment; probability judgment; focalism; support theory; overconfidence

\section{Introduction}

People must often make judgments that require specific comparisons. How good was Rebecca's poem relative to Melissa's and Casey's? For the security of bridges in this city, how high of a priority is the Adam's street bridge? Between you and your spouse, what proportion of housework do you do? How do you rank relative to your peers on intelligence? Given the fixed amount for the merit raise pool, what should Alex's raise be? What is the probability that a patient has Disease $X$, rather that $Y$ or $Z$ ? These questions require what we call referent-specific judgments—i.e., judgments for which a target must be judged relative to a referent or set of referents that are specified or clearly implied. Referent-specific judgments can be distinguished from other types of judgments that not referent-specific. If asked How charismatic was Prime Minister May?, a respondent is free to use various referents in an undefined way (e.g., compared to her last appearance, compared to other world leaders, compared to a prior expectation). This paper focuses exclusively on referent-specific judgments. As illustrated by the examples above, referent-specific judgments come in many 
forms, including comparative assessments, subjective probabilities, proportion estimates, and ranks.

Research on various forms of referent-specific judgments has revealed biases that seem to share structural characteristics, even though the biases go by different names. Consider the following examples:

1) People are prone to overestimating the comparative standing of items drawn from sets of high quality items (Bruchmann et al., 2013; Chambers, 2010; Giladi \& Klar, 2002; Klar, 2002; Posavac, Brakus, Cronley, \& Jain, 2009; Posavac, Brakus, Jain, \& Cronley, 2006; Suls et al., 2010; Windschitl, Conybeare, \& Krizan, 2008). In a seminal study, individual soaps drawn randomly from a set of high quality soaps tended to be rated as more pleasant than others in the set (Giladi \& Klar, 2002). This effect, dubbed the nonselective superiority bias, has a compliment called the nonselective inferiority bias, in which people tend to rate items drawn from low a quality set as worse than the others in that set (Giladi \& Klar, 2002). Related implications for resource valuations/allocations under fixed-pie scenarios have also been detected (Posavac et al., 2006; 2010).

2) People often overestimate probabilities. The estimated probabilities for events from a set of three or more mutually exclusive and exhaustive events tend to sum to more than 1.0, which necessarily reflects overestimation (e.g., Dougherty \& Hunter, 2003a, 2003b; Posavac, Kardes, \& Brakus, 2010; Riege \& Teigen, 2013; Robinson \& Hastie, 1985; Sanbonmatsu, Posavac, \& Stasney, 1997; Sprenger et al., 2011; Teigen, 1974, 1983; Tversky \& Koehler, 1994). Terms like additivity neglect and subadditivity have been used to describe/explain this effect (Riege \& Teigen, 2013; Tversky \& Koehler, 1994).

3) In studies on unrealistic optimism, people often report being less likely to experience negative events than are their peers (Weinstein, 1980). This effect depends, in 
part, on event rarity. The effects are strongest for very rare events and can sometimes reverse for events that are common (Chambers et al., 2003; Kruger \& Burrus, 2004).

4) In studies on above-average effects, people often report being better at tasks than their peers, but this depends on the overall difficulty of those tasks (Kruger, 1999; Larrick, Burson, \& Soll, 2007; Moore, 2007). The effects are strongest for easy tasks and can reverse for difficult tasks. Similarly, research on shared-circumstance effects show that contestants become more optimistic about winning (i.e., outperforming the competition) when salient shared circumstances are easy (e.g., a tail wind in a bike race) than difficult (e.g., a head wind) (e.g., Moore \& Kim, 2003; Windschitl et al., 2003).

Whereas these biases all have different names and may seem to involve various types of judgments, the judgments are all referent-specific, and we believe these biases share core characteristics. Previous papers have linked pairs or subsets of these biases (e.g., Chambers \& Windschitl, 2004; Posavac et al., 2010; Riege \& Teigen, 2015; Sanbonmatsu et al., 2011) but we know of no paper providing a framework for relating and understanding all of these effects. That is, papers have not theorized about referent-specific judgments as a class of judgments.

In this paper, we introduce a general framework for understanding referent-specific judgments and their biases. This framework, called the Referent-Specific Judgment Framework (RSJF), is not intended to replace prior explanations for bias in reference-specific judgments. Instead, the framework builds upon and helps to organize these prior explanations. Below, we start by discussing how, across the multitude of individual accounts for bias in referent-specific judgments, sources of bias can be gainfully categorized into two types — weighting biases and aggregation biases. Next, we describe the processing steps assumed by RSJF and explicate how the weighting and aggregation biases fit within that framework. For our empirical studies, we tested predictions about similarities and 
differences in the biases exhibited by two major types of referent-specific judgmentscomparative and probability judgments.

\section{Organizing Sources of Bias from Prior Accounts into Two Types}

There are numerous accounts addressing bias in various forms of referent-specific judgments. Some of these accounts can sound quite distinct from each other, even when a careful examination reveals that they essentially point to the same key mechanism. Here, we point out that sources of bias identified in previous accounts can be categorized into two types.

Bias Type 1: Misweighting (Neglecting) the Referent(s)

Many accounts either implicitly hint or explicitly state that when people are asked to make a referent-specific judgment about a target, they tend of focus primarily on evidence about the target, thereby neglecting to adequately consider evidence about the referent(s). This misweighting/neglect of referents ultimately leads to judgments that are generally too high (low) when made about targets and referents that are generally high (low) in favorable evidence. For example, if people’s ‘comparative’ judgments about a randomly selected target soap from a set of great soaps are primarily about the target and not the referents, then those judgments will tend to be too high—suggesting an illogical view that soaps tend to be better than the sets from which they came. This misweighting or referent-neglect idea is relevant in several partially overlapping accounts, including focalism (e.g., Windschitl et al., 2003), myopia (e.g., Moore \& Kim, 2003), selective-hypothesis testing (Posavac et al., 2010; Sanbonmatsu, Posavac, Kardes, \& Mantel, 1998), differential weighting (Windschitl et al., 2008), anchoring and insufficient adjustment (Kruger, 1999), unique attributes (Chambers, 2010), group diffuseness and singular-target focus (Klar \& Giladi, 1997; Suls et al., 2010), egocentrism (e.g., Kruger, 1999), and reference-group neglect (e.g., Camerer \& Lovallo, 1999; see also Fox \& Levav, 2000; McKenzie, 1998; Windschitl, 2000; Yamagishi, 2002). 
These accounts differ in various ways. Some are distinct in their emphasis on specific processes that lead to referent neglect (e.g., anchoring, unique attributes). Some are distinct in that they attribute the neglect of referents to situations in which the referents are a group rather than singleton (group diffuseness and singular-target focus). Some are relevant specifically to when the target is the self or self-relevant (e.g., egocentrism). Nevertheless, they share the notion that there are times when people neglect to adequately consider/weight evidence about the referent(s).

This misweighting or referent-neglect idea is also implicitly shared by two additional accounts, one addressing comparative judgments and one addressing probability judgments. Giladi and Klar's (2002) Local Comparisons General Standards Model (LOGE) suggest that when a person is asked to judge an individual item from a group compared to the rest of the items in the group (e.g., how good is this soap compared to others on the table), they partly compare the target entity to a general standard (all soaps in memory). Hence, people partially neglect the specific referents (soaps on the table) in the sense that they let their judgment be influenced by comparison processes that are not about the specified referents. The other theory, called Extended Support Theory, addresses probability judgments (EST; Idson et al., 2001; for support theory see Rottenstreich \& Tversky, 1997; Tversky \& Koehler, 1994). It posits that when people are estimating probability, they not only compare evidence for the focal hypothesis to evidence for the residual (the referents), they also compare to a general standard (see ' $\mathrm{K}$ ' in the EST formalization; Idson et al., 2001). Again, this essentially represents a partial neglect of the referent hypothesis(es).

\section{Bias Type 2: Aggregation Errors}

This second type of bias concerns how people judge evidence about referents when there are more than one referent. Some of the accounts mentioned above assume that when people are judging a target with multiple referents, the difficulty in handling evidence from 
multiple referents causes people to neglect the referents. However, another type of possibility (i.e., Bias Type 2) is that people imperfectly aggregate or estimate the evidence associate with the referents. One account for comparative judgments suggests that as the size of a referent group increases, the tendency to underestimate the extremity of the group or to regress the evaluation of the group to a moderate level increases (Chambers \& Windschitl, 2004; Krueger \& Mueller, 2002; Moore, 2007). Other accounts suggest it is possible for the evaluation of a group average to be more extreme than warranted (e.g., Suls et al., 2010; Windschitl et al., 2008; see also Price, Smith, \& Lench, 2006; Smith \& Price, 2010). To explain overestimation in probability judgments, support theory focused on subadditivity effects, which are essentially based on misjudgments of evidence for implicitly represented referents (Rottenstreich \& Tversky, 1997; Tversky \& Koehler, 1994). According to support theory, the perceived support for the components in a residual hypothesis will be less than it should be, which in turn makes the judged probability of the focal hypothesis greater than it should be (although see Redden \& Frederick, 2011; Sloman et al., 2004).

\section{Processes and Biases in the Referent-Specific Judgment Framework (RSJF)}

The recognition that there are two basic categories of bias helps make sense of what might otherwise be a confusing patchwork of terms and conceptualizations. Here, we hope to provide more structure by outlining the simple processes assumed in RSJF and by locating those two sources of bias within that process framework.

Again, the RSJF applies to when a target must be judged relative to a referent or set of referents that are specified or clearly implied. We've already mentioned a diversity of examples, but for extended illustration, we will add two more examples of referent-specific questions. The first asks for a comparative judgment: 'How high is the rate of calories per serving in a Taco Bell Burrito Supreme compared to a Big Mac or Dairy Queen Blizzard?’ (from much lower to much higher). The second is very similar but it asks for a probability 
judgment: 'What is the likelihood that a Taco Bell Burrito Supreme, rather than a Big Mac or Dairy Queen Blizzard, has the highest rate of calories per serving? (from 0\% to 100\%).'

RSJF assumes that people spontaneously evaluate the target (and to some extent the referents) on the dimension relevant to the question (see Step 1 in Figure 1). For example, by the time you finished reading either question about the Big Mac, Blizzard, and Burrito Supreme, you probably already had the strong sense that these were high calories foods. This impression that they are high calorie foods is a result of comparing the evidence for each against a general norm, which is akin to ' $\mathrm{K}$ ' in EST (Idson et al., 2001) or the general standard from LOGE (Giladi \& Klar, 2002; see also Kahneman \& Miller, 1986). Unless the relevant evidence is complex or requires an evidence search, this comparison against a general norm is spontaneous and a product of what could be called System 1 processing (Kahneman, 2003; Stanovich \& West, 2000; see also Sloman, 1996). This impression about the target also spontaneously influences response formation. The fact that people would immediately evaluate a Burrito Supreme as high in calories can impact their initial thoughts and inclinations about how to respond.

[Figure 1 near here]

However, RSJF also assumes that people might go beyond spontaneous processing. Regarding our Burrito Supreme example, people would recognize that the question requires a specific comparison, not an effortless initial impression. Consequently, RSJF includes a Controlled Comparison Step. The cognitive demands of this step can vary depending on the number of referents, type of judgment, and characteristics of the evidence. If the question being posed to a respondent has more than one referent or a compound referent, then the controlled-comparison step might involve an aggregation substep, in which the respondent attempts to gauge the overall strength or amount of evidence represented by the full referent(s). In the case of probability judgments, this aggregation should (normatively) be 
additive or quasi-additive (Tversky \& Koehler, 1994). In the case of a comparative judgment, the aggregation should approximate a mean or median value. An aggregation substep isn’t required when there is just one referent. Yet, even with the simplest of judgments— such as a comparison of one target to one referent—some degree of controlled processing would still be important. Two items might be reflexively compared on any number of characteristics, but the judgment question would require a narrowing of attention down to how the two items compare on a specified dimension (e.g., calories).

As can be seen in Figure 1, RSJF posits that both the spontaneous and controlled steps can yield inputs into how people might judge a target. Critically, only the second, controlled input is normatively relevant. A perfect judge should ignore his/her spontaneous impression based on how a target compares against a general standard and formulate a response based entirely on how the target compares with the referents. That is, the controlled input should entirely supersede the spontaneous input. Given that making specified comparisons usually requires cognitive control and that managing to ignore or discount a spontaneously generated impression also requires control, we assume that if a person is lacking in either motivation or cognitive resources, then the chance that the controlled input would fully supersede the spontaneous input would be unlikely.

Any lingering influence from the spontaneous input means that, in determining the observed response, evidence regarding the target will have had more weight than evidence regarding the referents. This is the same as what we identified earlier as the misweighting or neglecting of the referent(s). Therefore, all of the prior accounts we listed for misweighting or referent neglect can also be understood through the RSJF, as describing instances in which the controlled input did not fully supersede spontaneous input, or more simply as times when general impressions about a target were too influential. Empirically, this bias would result in a pair of effects: overestimations about targets from a set of entities or hypotheses that are 
generally high in evidence (as in the Burrito Supreme—Big Mac—Blizzard example) and underestimations about targets from a set of entities that are generally low in evidence (imagine a broccoli-apple-tofu example).

Independent of this bias, people’s observed responses can also be biased by systematic aggregation errors. In other words, the input from the controlled comparison step was incorrect because the aggregation substep simply left people with an inaccurate estimation of the evidence for the referents (when there are multiple referents). Empirically, there are a variety of shapes this bias could take, which are addressed more when we discuss predictions for our studies. Again, for probability judgments, approximating the additive evidence across referents is critical for making an unbiased judgment. For comparative judgments, the approximating the mean or median is critical.

\section{Overview of Empirical Studies, Paradigm, and Predictions}

Thus far, we have built the case for RSJF on primarily a logical basis. Is there empirical evidence that various forms of referent-specific judgments are similar enough to be classified together and described under one framework? Most papers focus on only one subtype of referent-specific judgment (although see Chambers \& Windschitl, 2004; Posavac et al., 2010; Price et al., 2006; Sanbonmatsu et al., 2011); direct tests of similarities and differences have not been emphasized. An important exception is Riege and Teigen (2015), who found that across small, separate sets of comparative and probability questions, overestimates were common and their magnitudes across the two judgment types were significantly correlated.

Here we present two studies that examined similarities and differences in biases affecting comparative and probability judgments, which are the two most widely studied types of referent-specific judgments. Specifically, the studies tested the magnitudes and moderators of the biases affecting these two judgments. RSJF helps organize predictions for 
these effects. The moderators that we tested included evidence strength, set size, time pressure, and topic domain. As discussed below, RSJF makes specific predictions for the first 3 of these moderator factors. The last factor of topic domain was included to test the generalizability of observed effects.

\section{The Paradigm Basics}

Our stimuli involved questions in 4 topic domains (movie ratings, foods calories, state populations, and surname frequencies). Within each domain, we tested parallel versions of probability and comparative judgments (see Table 1). For example, for a given item in the food domain, participants would see a list of foods, with one designated as the target. They would answer either a probability or comparative question (i.e., either estimate the probability that the target food was the highest calorie food, or give a comparative estimate of the calorie amount in the target food relative to the other foods on the list). There were two other critical manipulations: A set of items was either generally strong (e.g., high calorie foods) or generally weak (e.g., low calories foods), and the size of a set was 2, 5, or 10 items. In summary, the key factors in our studies were question type (probability or comparative), set strength (strong or weak), set size (2, 5, or 10), and topic domain (movies, calories, states, surnames). Time pressure was a key factor added to Study 2.

[Table 1 near here]

Visual-analogue scales, scored 0-100, were used with appropriate anchor labels (see Figure 2). Counterbalancing ensured that, for each set, each item was the target equally often. This allowed us to compare mean responses to normative means. For example, if half of the participants are asked the likelihood that Movie A is better and half are asked if Movie $\mathrm{B}$ is better, the average of responses should be 50\%. More generally, the normative probability averages should be $1 /$ (set size), or $50 \%, 20 \%$, and $10 \%$ for set sizes of 2,5 , and 
10, respectively. For comparative judgments, the normative average for responses is always at the midpoint of the response scale (50 for the scoring we used)—regardless of set size.

[Figure 2 near here]

\section{Predictions}

Below we outline three specific predictions for Study 1, which were inspired by RSJF as well as previous empirical results and accounts. Overall, these three predictions instantiate the RSJF expectation that weighting biases, but not aggregation biases, would operate in largely the same way for comparative and probability judgments.

The solid lines in Figures 3 and 4 illustrate these predictions in terms of expected results. The dotted lines in those figures depict normative averages (i.e., what the group averages would be if there were no biases), which are necessarily different for comparative and probability judgments.

Prediction 1: For both comparative and probability judgments, there will be a strong-weak effect-even in binary cases.

RSJF assumes that people spontaneously evaluate the evidence for the target with respect to a general standard, and the result influences referent-specific judgments in a biased way, which RSJF calls a weighting bias. This leads to the prediction that judgments about a strong target relative to a strong referent(s) will be too high while judgments about a weak target relative to a weak referent(s) will be too low. This pattern is what we will call a strong-weak effect. RSJF assumes this weighting bias, manifested in the strong-weak effect, can obtain even when there is only one referent (a set size of 2). There is already some empirical support for the idea that both comparative and probability judgments can be vulnerable to strong-weak effects, even in binary cases (e.g., Macchi et al., 1999; Suls et al., 2010), but the present study was the first to test for the bias in both types of judgments within the same experiment. 
Prediction 2. The magnitude of the strong-weak effect will be similar for comparative and probability judgments and for different set sizes.

In Figures 3 and 4, this prediction is represented by the fact that degree of separation between the strong and weak lines is similar across both judgment types and all set sizes. A key premise of RSJF is that, when it comes to the spontaneous processes that yield weighting biases, referent-specific judgments are similar. Given that the strong-weak effect is driven by weighting bias and not aggregation bias, the effect should be of similar magnitude for comparative and probability judgments. Our expectation is inspired by findings on comparative judgments suggesting that they are just as strong in binary cases as they are in cases with multiple referents (Studies 1 \& 2 of Suls et al., 2010; but see also Studies 4 \& 6). However, an interesting alternative is that the strong-weak effect might increase with set size because, as the number of items in a set increases, the strength or weakness of a set of referents becomes more difficult to assess. People then rely more heavily on input from impressions than input from the controlled comparison step. In other words, the weighting bias, manifested as the strong-weak effect, could be larger when the set size is high rather than low.

[Figure 3 near here]

[Figure 4 near here]

Prediction 2 implies that systematic misaggregation will not interact with set strength. If misaggregation worked differently for weak versus strong sets, then the strong-weak effect would differ across set size. For example, imagine that for strong items, people tend to underestimate groups of referents (i.e., misaggregate in a downward direction), leading to overstimates about targets. Also imagine that for weak items, people tend to overestimate groups of referents (i.e., misaggregate in an upward direction), leading to underestimates about targets. If these imagined (and conceptually plausible) possibilities co-occurred, the 
strong-weak effect would be greater when set sizes were greater than, rather than equal to two.

Prediction 3. There will be no general overestimation bias among comparative judgments at any set size. However, among probability judgments, a general overestimation bias will be observed with set sizes greater than two, and it will increase with the size of the set.

Imagine that, in Figure 3, there was a line representing the combination of the strong and weak lines. This line would entirely overlap the normative line, even for set sizes of 5 and 10. This represents our expectation that systematic over-aggregation is not a problem with comparative judgments. While people might misaggregate in a noisy way, this noise won't accumulate to systematically bias judgments in an upward direction. In fact, various studies suggest that as a group of stimuli increase in number, the estimate of the mean or rating of the group of stimuli can increase (Price, Smith, \& Lench, 2006; Price et al., 2014; Smith \& Price, 2010; Windschitl et al., 2008). The direction of this effect would, if anything, push target judgments lower as the set size increased.

The situation is different for probability judgments. Imagine that, in Figure 4, there was a line representing the combination of the strong and weak lines. This line and the normative line would start at the same location for set size 2, but the predicted line would increasingly drift above the normative line for set sizes 5 and 10. That is, the general tendency to overestimate probabilities starts when there is more than one referent (set size 5 in our study) and increases with the size of the set. This predicted trend is attributed to misaggregation of the referent items. With probability judgments, aggregation of the referents should be an additive (or at least quasiadditive) process. However, consistent with support theory, we expect that errors of subadditivity will be more common (leading to overestimation of probability) than will errors of superadditivity (e.g., see Macchi et al., 1999; Tversky \& Koehler, 1994). ${ }^{1}$ 


\section{Experiment 1}

\section{Method}

Participants and Design

Students $(N=160)$ participated as part of a research exposure component of their introductory psychology course. The design was a 2 (Question Type: Probability or Comparative) x 2 (Set Strength: Strong or Weak) x 3 (Set Size: 2, 5, or 10) x 4 (Domain: Movie, Foods, States, Surnames) mixed factorial. Question type was the only betweensubjects factor. Various counterbalancing was used (e.g., half the participants saw strong movies and states and weak foods and surnames, while the other half saw the opposite; items from a domain served a focal [vs. referent] role with approximately equal frequency).

In addition to the primary factors listed above, we also manipulated a pre-task and timing variable. The procedures involved with these two factors are mentioned briefly in the next section (with additional details in footnotes), but because neither of these two factors produced main effects or interactions, we collapse those factors when describing results. Materials and Procedure

After initial instructions and a pre-task, ${ }^{2}$ participants encountered the key questions (one per screen). The items used for a given question (e.g., the set of 5 movie titles) were always presented in a vertical list that was randomized per participant (see Appendix for the items). When the list appeared, the focal item was immediately or soon denoted with a red font color. ${ }^{3}$ A probability or comparative question appeared below the list (see Table 1 and Figure 2 for examples). Participants made a total of 12 referent-specific judgments—one per set size-domain combination. Finally, they made absolute judgments for each of the individual stimulus items before being debriefed and dismissed. ${ }^{4}$

\section{Results}

The data files for both studies can be accessed at: https://osf.io/qy3gu/ 
Preliminary analyses revealed that results were generally consistent across the four domains (i.e., no significant interactions with domains). Therefore, for simplicity, we collapse across domain in reporting our main analyses below. In preparing for our main analyses, we computed six composite judgments per participant-reflecting the participant's average responses for strong or weak sets of sizes 2, 5, or 10. Participants' average judgments are plotted in Figures 5 and 6.

[Figure 5 near here]

[Figure 6 near here]

Prediction 1 had two parts, with the first part being that probability and comparative judgments would show a strong-weak effect. To test this, we conducted a 2 (Question Type) x 2 (Set Strength) x 3 (Set Size) repeated-measures ANOVA. As predicted, there was a main effect of set strength; participants gave higher referent-specific judgments to strong sets than weak sets, $F(1,158)=31.02, p<.001, \eta_{\mathrm{p}}{ }^{2}=.164$. Follow-up tests revealed that the strongweak effect was significant for comparative judgments $(p<.001)$ and probability judgments $(p<.001)$. Other follow-ups confirmed the second part of Prediction 1: The strong-weak effect at set-size 2 was significant for both comparative judgments $(p=.03)$ and probability judgments $(p=.001)$.

Consistent with Prediction 2, the effect of set strength was not significantly different between comparative and probability judgments, $F(1,158)=0.09, p=.77, \eta_{\mathrm{p}}{ }^{2}=.001$. It also did not vary as a function of set size, $F(2,157)=0.33, p=.72, \eta_{\mathrm{p}}{ }^{2}=.004$. This was also true when analyzing the comparative and probability judgments separately (both Fs $<1$ ).

Recall that Prediction 3 stated that there would be no general overestimation bias for comparative judgments regardless of set size, and that for probability judgments there would be a general overestimation bias at set sizes 5 and 10. To test this prediction, we averaged the participants' judgments regarding the strong and weak sets separately for the three set 
sizes. For comparative judgments, we then compared this value to 50 (i.e., the scale midpoint). As predicted, there was no general overestimation for the judgments at any of the set sizes. In fact, there was a slight tendency towards underestimation. Participants' average judgments for set sizes of $2(M=48.73, S D=11.59)$ and $5(M=48.86, S D=10.18)$ were not significantly below 50 ( $p=.33$ and $p=.16$, respectively) while judgments for set size of 10 $(M=46.86, S D=9.90)$ were significantly below $50, t(78)=2.82, p=.006, d=0.32$.

To test the part of Prediction 3 that deals with probability judgments, we compared the participants' average judgments from set sizes of 2, 5, and 10 to 50, 20, and 10, respectively. As predicted, there was no general overestimation with set size $2(M=46.29$, $S D=12.48)$. Similar to the comparative judgments, this value was below $50, t(80)=2.68, p$ $=.009, d=0.30$. In contrast to the slight underestimation with a set size of 2 , the judgments with set sizes of $5(M=31.10, S D=12.23)$ and $10(M=24.33, S D=13.91)$ were significantly above 20 and 10, respectively (both $p s<.001$ ) - a pattern that supports Prediction 3.

\section{Discussion}

The results from Study 1 were consistent with the three key predictions. 1) Strongweak effects were observed for both judgment types (probability and comparative), even for binary cases. 2) The strong-weak effects were similar across judgment type and set sizes. 3) There was an overall tendency towards overestimation only with probability judgments, not comparative judgments, when aggregation was required (i.e., set sizes of 5 and 10 rather than 2). These findings are consistent with RSJF's expectation that weighting biases—which account for the strong-weak effects—operate in largely the same way for comparative and probability judgments, whereas aggregation biases do not. Notably, these findings were similar across four different question domains (movies, food, states, surnames).

\section{Experiment 2}


The results of Experiment 1 provide initial support for RSJF, but a critical assumption of the framework has yet to be tested. RSJF assumes that the evaluations of the target and referent(s) are relatively automatic, yet making the specific comparison of the target with the referent(s) is controlled and effortful. Experiment 2 tested this assumption by using time pressure to limit participants' ability to engage in the controlled comparison stage.

\section{Predictions regarding the influences of time pressure}

Prediction 4: Time pressure will increase the strong-weak effect for both comparative and probability judgments.

RSJF posits that weighting biases occur when participants’ judgments are primarily determined by impressions or input from spontaneous processes rather than input from the controlled comparison processes. Therefore, because controlled processes (including the discounting of response inclinations driven by spontaneous processes) takes time and cognitive resources, weighting biases should be more extreme when judgments are made under time pressure than when there is plenty of time available. Given that the strong-weak effect is a manifestation of a weighting bias, RSJF predicts that time pressure should magnify the strong-weak effect. Moreover, RSJF assumes this magnification will be approximately the same for comparative and probability judgments.

Prediction 5: For probability judgments, overestimation will increase under time pressure for Set Sizes 5 and 10.

Recall that in Study 1, overestimation of probability estimates increased with set size as a result of the aggregation bias. For Study 2, we expected this effect of the aggregation bias to be exacerbated under time pressure. Time pressure would limit the participants’ ability to engage in an additive aggregation process and consequently decrease the perceived strength of the referent group (i.e., increase subadditivity). This should, in turn, increase the amount of overestimation in participants' probability judgments. Because subadditivity is 
only relevant when there is more than one referent, we expected that time pressure would increase overestimation only for set sizes greater than 2 .

Because the aggregation process for comparative judgments does not require additivity, a systematic, overall increase in judgments is not expected.

\section{Prior Research Relevant to Predictions 4 and 5}

Various pockets of research provide limited background for Predictions 4 and 5. Kruger (1999) found that above- and below-average effects were exacerbated under a cognitive load, which, like time pressure, restricts elaborated processing. However, there are a host of differences between Kruger’s study and ours (e.g., differential knowledge: people know more about the self than their peers), making those findings of only limited relevance here. Sanbonmatsu, Vanous, Hook, Posavac, and Kardes (2011) investigated the influence of time pressure on information use and probability judgments about one of four hypothetical job candidates. When participants had limited time to process information (45 sec rather than $10 \mathrm{~min}$ ), they spent a greater proportion of their time attending to information about the target (vs. referents), but the manipulation did not have an overall impact on probability judgments. Finally, Sprenger et al. (2011) found that participants’ probability estimates in a foodfrequency learning paradigm were higher under increased cognitive load. This extended findings showing that working memory capacity is negatively related to probability estimates in such tasks (Dougherty \& Hunter, 2003a, 2003b; Sprenger \& Dougherty, 2006). All of these findings provide general inspiration for the notion that controlled processing is important in referent-specific judgments, but the findings come from substantially different paradigms and do not involve the types of comparisons our study does (comparative versus probability judgment; sets of various sizes).

\section{Method}

Participants and Design 
Students $(N=219)$ participated as part of a research component of their introductory psychology course. The design of the experiment was a 2 (Question Type: Probability or Comparative) x 2 (Set Strength: Strong or Weak) x 3 (Set Size: 2, 5, or 10) x 4 (Domain: Movie, Foods, States, and Surnames) x 2 (Time Pressure: No vs. Yes) mixed factorial. Procedure

The procedures were the same as in Experiment 1 with a few exceptions. The most important change concerns the time pressure manipulation. Participants who were in the pressure condition were allowed to examine the sets of 2, 5, and 10 items for 2, 4, and 8 seconds, respectively. After the time limit expired, the set disappeared and was replaced with a prompt to 'respond immediately.' Participants in the no pressure condition were allowed to examine the set of items as long as they felt necessary before making their judgments. A second change was that participants were shown the comparative or probability question before the set of items was displayed. Each trial started with the question displayed on the top of the screen. The question itself did not specifically state the focal item, but it referred to the item that would appear in red when the set appeared. Once the participant clicked on a 'continue' button, the items were displayed in a vertical list, with the response scale below. For the time-pressure condition, the items disappeared at the time limit, but scale remained for participants to respond.

\section{Results and Discussion}

The results were generally consistent across the four domains, so we again collapse across domain in reporting our main analyses. Results for comparative and probability judgments are plotted in Figures 7 and 8, respectively.

[Figure 7 near here]

[Figure 8 near here] 
For efficiency and clarity, we focus primarily on analyses that are most relevant to our two key predictions. First, however, we note that, consistent with Study 1, participants gave higher estimates for the strong items than the weak items, $F(1,215)=52.39, p<.001, \eta_{\mathrm{p}}{ }^{2}=$ .20, and this strong-weak effect did not significantly vary as a function of judgment type $(F<$ 1).

Critically, in support of Prediction 4, there was a significant Set Strength x Time Pressure interaction, $F(1,215)=14.66, p<.001, \eta_{\mathrm{p}}{ }^{2}=.06$. Participants under time pressure exhibited a larger strong-weak effect than participants not under time pressure.

Prediction 5 stated that general overestimation for set sizes of 5 and 10 would increase under time pressure for probability judgments. As in Study 1, participants exhibited significant overestimations with set sizes of $5(M=28.47$ rather that the standard of 20.00, $S D=11.26, p<.001, d=0.75)$ and $10(M=21.40$ rather than the standard of $10.00, S D=$ 12.36, $p<.001, d=0.92$ ). As expected, this overestimation was significantly greater under time pressure than no time pressure for set sizes of $5\left(p=.03, \eta_{\mathrm{p}}{ }^{2}=.04\right)$ and $10\left(p=.06, \eta_{\mathrm{p}}{ }^{2}=\right.$ .03). For set sizes of 2 , there was actually underestimation $(M=43.66$ rather than the standard of 50.00, $S D=10.90, p<.001, d=0.58$ ), and this underestimation was not affected by time pressure $\left(p=.61, \eta_{\mathrm{p}}^{2}=.002\right)$. The 3 (Set Size) $\times 2$ (Time Pressure) interaction approached but did not reach significance, $F(2,107)=2.49, p=.09, \eta_{\mathrm{p}}^{2}=.04$.

Prediction 5 did not anticipate analogous results for comparative judgments. Indeed, general overestimation did not increase as a function of time pressure for set sizes of $5(M=$ 49.37 rather that the standard of 50.00, $S D=9.51, p=.49, d=.06)$ and $10(M=48.20$ rather than the standard of 50.00, $S D=9.83, p=.06, d=.18$ ). A 3 (Set Size) x 2 (Time Pressure) ANOVA on comparative judgments revealed only a main effect of Set Size, $F(2,106)=4.88$, $p=.009, \eta_{\mathrm{p}}{ }^{2}=.08$, indicating an overall reduction in estimates as set sizes increased. This follows a similar but nonsignificant trend observed in Experiment 1; it might be attributable 
to inflation in the impression of the referents as the number of referents increases (see e.g., Price et al., 2006; 2014; Smith \& Price, 2010; Windschitl et al., 2008). More germane to the present context is that, as expected, neither time pressure nor the Set Size x Time Pressure interaction was significant (both $p s>.45$ ).

In summary, the results of Experiment 2 are consistent with the predictions regarding the influence of time pressure. In support of Prediction 4, the strong-weak effect was magnified when under time pressure for both probability and comparative judgments. In support of Prediction 5, the time pressure manipulation enhanced the tendency to overestimate when making probability judgments for which an aggregation substep is required (set sizes of 5 and 10), but not when aggregation is not required (set size of 2).

\section{General Discussion}

At the start of this paper, we introduced the term referent-specific judgments and argued that there is important utility to considering them as a class of judgments. We proposed the RSJF as a tool for understanding similarities and differences among judgments within this class and for synthesizing the accounts of relevant biases. RSJF is only useful if biases in referent-specific judgments exhibit the types of empirical similarities suggested by RSJF. For our empirical studies, we choose to compare two important types of referent specific judgments — comparative and probability judgments. We examined how these judgments were impacted by key, potential moderator variables (evidence strength, set size, time pressure, and topic domain). The pattern of findings revealed that biases in probability judgment and comparative judgment are empirically similar in precisely the ways that RSJF anticipates, yet different in ways also specified by RSJF.

The empirical similarity is evident in how a weighting bias manifests in both comparative and probability judgments as a strong-weak effect, and how this effect responds similarly in the two types of judgments to manipulations of set size and time pressure. More 
specifically, the strong-weak effect did not vary as a function of set size in either type of judgment. Furthermore, time pressure increased the magnitude of the effect in both types of judgment, presumably because it limited participants’ abilities to engage in, or restricted input from, the controlled comparison step. Another type of similarity anticipated by RSJF is that key data patterns were highly similar across the four topic domains (movies, foods, states, and surnames).

The dissimilarities concern the aggregation bias. In non-binary cases, probability judgments—but not comparative judgments—-tend to be systematically overestimated. This difference is not due to weighting biases, which push responses from strong and weak sets in opposite directions, thus cancelling out in overall analyses. The difference is due to: 1) people fall short of doing the additive aggregation of referents that is required for probability judgment (e.g., Tversky \& Koehler, 1994), and 2) people do not fall short when estimating the referents for making a comparative judgment. If anything, they slightly overestimate the average from a groups of referents and give focal estimates that are too small (see both Studies 1 and 2; see also Price et al., 2006). As expected, time pressure enhanced general overestimation when additive aggregation is required (probability judgments in non-binary cases) but not when additive aggregation is not required (all judgments in binary cases; all comparative judgments).

In summary, the studies revealed the expected empirical similarities and dissimilarities associated with comparative and probability judgments. All moderators impacted judgments as anticipated through the lens of the RSJF. The results support the idea that RSJF is useful for understanding referent-specific judgments as a class of judgments.

\section{Umbrella for Other Accounts}

RSJF is not meant to be a replacement for previous accounts. It borrows elements from existing theoretical perspectives on biases affecting referent-specific judgments, most 
notably EST (Idson et al., 2001) and LOGE (Giladi \& Klar, 2002). It also extends those perspectives by specifying shared processes involved in probability, comparative, and other referent-specific judgments. Our description of RSJF provides relatively basic processing details, which lends some specificity but maintains its status as a framework or umbrella rather than a formal theory. Critically, the RSJF lends clarity to a distinction between weighting and aggregation biases that had not been adequately addressed. With RSJF, it is now more easy to organize and relate the plethora of terms developed in separate literatures that have been applied to various forms of referent-specific judgments (e.g., focalism, myopia, selective-hypothesis testing, unique attributes, generalized-group account, subadditivity; see citations for these terms in the Introduction). For example, RSJF makes it easier to understand that focalism and subadditivity are quite different; focalism is tied to weighting biases whereas subadditivity is tied to aggregation biases. Meanwhile, it reveals that a generalized-group account could have two versions — one that is tied to weighting and one that is tied to aggregation problems.

\section{Other Referent-Specific Judgments}

The current studies focused on comparative and probability judgments, but RSJF can apply to other types of referent-specific judgments. One type is a budget allocation judgment. To provide an unbiased budget allocation for a particular item, one should evaluate information about all the items and then determine a response based on a comparison of the focal item's worth as compared to the other items. However, as demonstrated by Posavac et al. (2006), people sometimes give inflated recommendations. When participants read descriptions of four National Parks and then indicated how much money from a limited budget should be allocated to one randomly selected park, the average allocation was over 25\% of the budget (see also, Posavac et al., 2010). Posavac et al. (2006) attributed this to selective focus on evidence regarding the target park, which is a specific version of the 
weighting bias in RSJF. According to RSJF, the effect could also be at least partly attributable to an aggregation bias. If entirely attributable to aggregation bias, which seems unlikely given the results we presented here, the overallocation effect should be insensitive to the average attractiveness of the national parks in the set—a variable that Posavac et al. (2006) did not manipulate.

More generally, any judgments that require the carving of a fixed pie can be considered referent specific. This includes frequency judgments when a total is specifiede.g., 'Out of 100 people who smoke...how many would die from lung cancer?' (Windschitl, 2002). It also includes proportional responsibility judgments, which can be especially important in legal contexts (Feigenson, Park, \& Salovey, 1997; Wissler, Kuehn, \& Saks, 2000; see also Teigen \& Brun, 2011). Subjective ranks are, by design, referent-specific judgments (e.g., Posavac, Kardes, Sanbonmatsu, \& Fitzsimons, 2005).

\section{RSJF and Self-Other Judgments}

None of the judgments in the current studies involved the self. However, there are many contexts in which referent-specific judgments involve the self as the target of judgment, with peers or others as referents. There are, in fact, research literatures devoted to biases affecting each of the following 3 types of questions (e.g., Alicke \& Govorun, 2005; Chambers, \& Windschitl, 2004; Chambers et al., 2003; Gilovich, Epley, \& Hanko, 2005; Kruger, 1999; Kruger \& Dunning, 1999; Kruger \& Savitsky, 2009; Larrick, Burson, \& Soll, 2007; Savitsky, Van Boved, Epley \& Wight, 2005; Weinstein, 1980):

1) comparative ability—e.g., How good are you compared to your peers?

2) comparative optimism—e.g., Compared to others, how likely are you to suffer X?

3) responsibility/contribution-e.g., What proportion of this task did you do?

Unlike with the other referent-specific judgments we have considered thus far, with self-vs.-other judgments, there is a strong potential for directional motives to play a role. 
People would typically prefer to view themselves as more skilled, less vulnerable, and more responsible for good outcomes relative to their peers (see e.g., Brown, 2012; Hughes \& Beer, 2013; Taylor \& Brown, 1988). Although RSJF is agnostic on the extent to which directional motives play a role within a given context, it remains useful as a framework for how these judgments are made and for locating the processing points at which motives could play a biasing role. For example, people might have an overly positive-and motivationally driven - initial evaluation of the self relative to a general standard. Or, they might tend to overweight an unflattering peer in an aggregation process.

Many studies have established that, for each of the three judgment types (comparative ability, optimism, and contribution), people do not always exhibit overly flattering biases. In fact, under well-defined circumstances, people will exhibit below-average effects, comparative pessimism, and overly humble responsibility estimates (Chambers et al., 2003; Kruger, 1999; Kruger \& Burrus, 2004; Kruger \& Savitsky, 2009; Moore, 2007; Rose, Suls, \& Windschitl, 2011; Roy, Liersch, \& Broomell, 2013). RSJF is useful for conceptualizing those effects. That is, RSJF can—without any directionally motivated effects assumed— account for both the flattering and unflattering directions of the biases. In the case of comparative ability judgments, Kruger (1999) established that people report being above average when the task or domain is generally easy, but below average when the task or domain is generally hard. Kruger attributed this to cognitive egocentrism, which is essentially a form of the weighting bias. People spontaneously register a general impression of their skill at the task, which influences their judgment because it is not fully superseded by the input from controlled processes in which a true comparison between self and peers is made. In some studies of comparative optimism judgments, people have tended to report being more vulnerable than others to negative events that are common (Chambers et al., 2003; Kruger \& Burrus, 2004; see also, Price, Pentecost, \& Voth, 2002). Again, this can be 
attributed to a weighting bias linked to egocentrism or focalism; people register a general impression of their vulnerability, which influences their judgment because it is not fully superseded by the input from controlled processes.

RSJF can accommodate other findings relevant to self-other judgments. For most self-vs.-other judgments, people have more knowledge about the self than about others (i.e., information about the former is more available, accessible, or both). Previous work suggests that this knowledge differential contributes to why self-relevant information is given more weight in the judgments process (Kruger, Windschitl, Burrus, Fessel, \& Chambers, 2008; Moore, 2007; Radevick \& Moore, 2013; Rose \& Windschitl, 2008; Rose, Windschitl, \& Smith, 2012; Windschitl et al., 2008). To explain this in RSJF, we assume that the high accessibility of information about the self is likely to produce strong spontaneous impressions, and the relative inaccessibility of information about others does little to trigger its consideration in the controlled comparison step. Also, manipulations that increase attention to peers in the judgment process tend to increase the impact of input from the controlled comparison step, thereby reducing the magnitude of observed biases (e.g., Chambers \& Suls, 2007; Krizan \& Suls, 2008; Moore \& Kim, 2003; Pahl, 2012; Pahl, Eiser, \& White, 2009; Windschitl et al., 2003, 2008).

\section{Conclusion}

Large bodies of research are devoted to referent-specific judgments of various sorts. However, much of this research has progressed independently, so the similarities and differences between various types of reference-specific judgments have been unclear. The current studies and the RSJF provide some clarity. The studies established direct empirical support for key similarities and differences between two of the most commonly studied forms of referent-specific judgments. The RSJF provides a tool for organizing what the disparate 
literatures on referent-specific judgments have already revealed, and it helps in the development of new hypotheses about this large class of judgments. 


\section{References}

Alicke, M. D., \& Govorun, O. (2005). The Better-Than-Average Effect. In M. D. Alicke, D. A. Dunning, J. I. Krueger (Eds.), The Self in Social Judgment (pp. 85-106). New York, NY, US: Psychology Press.

Balcetis, E. (2008). Where the motivation resides and self-deception hides: How motivated cognition accomplishes self-deception. Social and Personality Psychology Compass, 2, 361-381. doi:10.1111/j.1751-9004.2007.00042.x

Brown, J. D. (2012). Understanding the better than average effect: Motives (still) matter. Personality and Social Psychology Bulletin, 38, 209-219. doi:10.1177/0146167211432763

Bruchmann, K., Suls, J., Lee, S., Rose, J. P., Krizan, Z., \& Windschitl, P. D. (2013). Searching for the limits and explanations of the nonselective superiority bias. Social Psychological and Personality Science, 4, 124-130. doi:10.1177/1948550612443387

Chambers, J. R. (2010). Why the parts are better (or worse) than the whole: The uniqueattributes hypothesis. Psychological Science, 21, 268-275. doi:10.1177/0956797609359509

Chambers, J. R., \& Suls, J. (2007). The role of egocentrism and focalism in the emotion intensity bias. Journal of Experimental Social Psychology, 43, 618-625. doi:10.1016/j.jesp.2006.05.002

Chambers, J. R., \& Windschitl, P. D. (2004). Biases in social comparative judgments: The role of nonmotivated factors in above-average and comparative-optimism effects. Psychological Bulletin, 130, 813-838.

Chambers, J. R., Windschitl, P. D., \& Suls, J. (2003). Egocentrism, event frequency, and comparative optimism: When what happens frequently is 'more likely to happen to me’. Personality and Social Psychology Bulletin, 29, 1343-1356. 
Camerer, C. F., \& Lovallo, D. (1999). Overconfidence and excess entry: An experimental approach. American Economic Review, 89, 306-318.

Dougherty, M. P., \& Hunter, J. E. (2003a). Hypothesis generation, probability judgment, and individual differences in working memory capacity. Acta Psychologica, 113, 263-282. doi:10.1016/S0001-6918(03)00033-7

Dougherty, M. P., \& Hunter, J. E. (2003b). Probability judgment and subadditivity: The role of working memory capacity and constraining retrieval. Memory \& Cognition, 31, 968-982. doi:10.3758/BF03196449

Feigenson, N., Park, J., \& Salovey, P. (1997). Effect of blameworthiness and outcome severity on attributions of responsibility and damage awards in comparative negligence cases. Law and Human Behavior, 21, 597-617. doi:10.1023/A:1024856613829

Fox, C. R., \& Levav, J. (2000). Familiarity bias and belief reversal in relative likelihood judgment. Organizational Behavior and Human Decision Processes, 82, 268-292. doi:10.1006/obhd.2000.2898

Giladi, E. E., \& Klar, Y. (2002). When standards are wide of the mark: Nonselective superiority and inferiority biases in comparative judgments of objects and concepts. Journal of Experimental Psychology: General, 131, 538-551.

Gilovich, T., Epley, N., \& Hanko, K. (2005). Shallow thoughts about the self: The automatic components of self-assessment. In M. D. Alicke, D. A. Dunning, J. I. Krueger (Eds.), The Self in Social Judgment (pp. 67-84). New York, NY, US: Psychology Press.

Hughes, B. L., \& Beer, J. S. (2013). Protecting the self: The effect of social-evaluative threat on neural representations of self. Journal of Cognitive Neuroscience, 25, 613-622. 
Idson, L. C., Krantz, D. H., Osherson, D., \& Bonini, N. (2001).The relation between probability and evidence judgment: An extension of support theory. The Journal of Risk and Uncertainty, 22, 227-249.

Kahneman, D. (2003). A perspective on judgment and choice: Mapping bounded rationality. American Psychologist, 58(9), 697-720. doi:10.1037/0003-066X.58.9.697

Kahneman, D., \& Miller, D. T. (1986). Norm theory: Comparing reality to its alternatives. Psychological Review, 93, 136-153. doi:10.1037/0033-295X.93.2.136

Klar, Y. (2002). Way beyond compare: Nonselective superiority and inferiority biases in judging randomly assigned group members relative to their peers. Journal of Experimental Social Psychology, 38, 331-351. doi:10.1016/S0022-1031(02)00003-3

Klar, Y., \& Giladi, E. E. (1997). No one in my group can be below the group's average: A robust positivity bias in favor of anonymous peers. Journal of Personality and Social Psychology, 73, 885-901.

Krizan, Z., \& Suls, J. (2008). Losing sight of oneself in the above-average effect: When egocentrism, focalism, and group diffuseness collide. Journal of Experimental Social Psychology, 44, 929-942. doi:10.1016/j.jesp.2008.01.006

Krueger, J., \& Mueller, R. A. (2002). Unskilled, unaware, or both? The better-than-average heuristic and statistical regression predict errors in estimates of own performance. Journal of Personality and Social Psychology, 82(2), 180-188. doi:10.1037/00223514.82.2.180

Kruger, J. (1999). Lake Wobegon be gone! The 'below-average effect' and the egocentric nature of comparative ability judgments. Journal of Personality and Social Psychology, 77, 221-232.

Kruger, J., \& Burrus, J. (2004). Egocentrism and focalism in unrealistic optimism (and pessimism). Journal of Experimental Social Psychology, 40, 332-340. 
Kruger, J., \& Dunning, D. (1999). Unskilled and unaware of it: How difficulties in recognizing one's own incompetence lead to inflated self-assessments. Journal of Personality and Social Psychology, 77, 1121-1134. doi:10.1037/0022-3514.77.6.1121

Kruger, J., \& Savitsky, K. (2009). On the genesis of inflated (and deflated) judgments of responsibility. Organizational Behavior and Human Decision Processes, 108, 143152. doi:10.1016/j.obhdp.2008.06.002

Kruger, J., Windschitl, P. D., Burrus, J., Fessel, F., \& Chambers, J. R. (2008). The rational side of egocentrism in social comparisons. Journal of Experimental Social Psychology, 44, 220-232. doi:10.1016/j.jesp.2007.04.001

Larrick, R. P., Burson, K. A., \& Soll, J. B. (2007). Social comparison and confidence: When thinking you're better than average predicts overconfidence (and when it does not). Organizational Behavior and Human Decision Processes, 102, 76-94. doi:10.1016/j.obhdp.2006.10.002

Macchi, L., Osherson, D., \& Krantz, D. H. (1999). A note on superadditive probability judgment. Psychological Review, 106, 210-214.

McKenzie, C. M. (1999). (Non)Complementary updating of belief in two hypotheses. Memory \& Cognition, 27, 152-165.

Moore, D. A. (2007). Not so above average after all: When people believe they are worse than average and its implications for theories of bias in social comparison. Organizational Behavior and Human Decision Processes, 102, 42-58. doi:10.1016/j.obhdp.2006.09.005

Moore, D. A., \& Kim, T. G. (2003). Myopic social prediction and the solo comparison effect. Journal of Personality and Social Psychology, 85, 1121-1135.

Pahl, S. (2012). Would I bet on beating you? Subtly increasing other-focus helps overcome egocentrism. Experimental Psychology, 59, 74-81. doi:10.1027/1618-3169/a000128 
Pahl, S., Eiser, J., \& White, M. P. (2009). Boundaries of self-positivity: The effect of comparison focus in self_-friend comparisons. The Journal of Social Psychology, 149, 413-424. doi:10.3200/SOCP.149.4.413-424

Price, P. C., Kimura, N. M., Smith, A. R., \& Marshall, L. D. (2014). Sample size bias in judgments of perceptual averages. Journal of Experimental Psychology: Learning, Memory, and Cognition, 40(5), 1321-1331. doi:10.1037/a0036576

Price, P. C., Pentecost, H. C., \& Voth, R. D. (2002). Perceived event frequency and the optimistic bias: Evidence for a two-process model of personal risk judgments. Journal of Experimental Social Psychology, 38, 242-252.

Price, P. C., Smith, A. R., \& Lench, H. C. (2006). The effect of target group size on risk judgments and comparative optimism: The more, the riskier. Journal of Personality and Social Psychology, 90, 382-398.

Posavac, S. S., Brakus, J., Cronley, M. L., \& Jain, S. (2009). On assuaging positive bias in environmental value elicitation. Journal of Economic Psychology, 30, 482-489. doi:10.1016/j.joep.2008.07.007

Posavac, S. S., Brakus, J., Jain, S., \& Cronley, M. L. (2006). Selective assessment and positivity bias in environmental valuation. Journal of Experimental Psychology: Applied, 12, 43-49. doi:10.1037/1076-898X.12.1.43

Posavac, S. S., Kardes, F. R., \& Brakus, J. J. (2010). Focus induced tunnel vision in managerial judgment and decision making: The peril and the antidote. Organizational Behavior and Human Decision Processes, 113, 102-111.

doi:10.1016/j.obhdp.2010.07.002

Posavac, S. S., Kardes, F. R., Sanbonmatsu, D. M., and Fitzsimons, G. J. (2005). Blissful insularity: When brands are judged in isolation from competitors, Marketing Letters, 16, 87-97. 
Redden, J. P., \& Frederick, S. (2011). Unpacking unpacking: Greater detail can reduce perceived likelihood. Journal of Experimental Psychology: General, 140, 159-167. doi:10.1037/a0021491

Riege, A. H., \& Teigen, K. (2013). Additivity neglect in probability estimates: Effects of numeracy and response format. Organizational Behavior and Human Decision Processes, 121, 41-52. doi:10.1016/j.obhdp.2012.11.004

Robinson, L. B., \& Hastie, R. (1985). Revision of beliefs when a hypothesis is eliminated from consideration. Journal of Experimental Psychology: Human Perception and Performance, 11, 443-456. doi:10.1037/0096-1523.11.4.443

Rose, J. P., Suls, J., \& Windschitl, P. D. (2011). When and why people are comparatively optimistic about future health risks: The role of direct and indirect comparison measures. Psychology, Health \& Medicine, 16, 475-483.

doi:10.1080/13548506.2011.555772

Rose, J. P., \& Windschitl, P. D. (2008). How egocentrism and optimism change in response to feedback in repeated competitions. Organizational Behavior and Human Decision Processes, 105, 201-220. doi:10.1016/j.obhdp.2007.08.003

Rose, J. P., Windschitl, P. D., \& Smith, A. R. (2012). Debiasing egocentrism and optimism biases in repeated competitions. Judgment and Decision Making, 7, 761-767.

Rottenstreich, Y., \& Tversky, A. (1997). Unpacking, repacking, and anchoring: Advances in support theory. Psychological Review, 104, 406-415.

Roy, M. M., Liersch, M. J., \& Broomell, S. (2013). People believe that they are prototypically good or bad. Organizational Behavior and Human Decision Processes, 122, 200-213. doi:10.1016/j.obhdp.2013.07.004 
Sanbonmatsu, D. M., Posavac, S. S., Kardes, F. R., \& Mantel, S. P. (1998). Selective hypothesis testing. Psychonomic Bulletin \& Review, 5(2), 197-220. doi:10.3758/BF03212944

Sanbonmatsu, D. M., Posavac, S. S., \& Stasney, R. (1997). The subjective beliefs underlying probability overestimation. Journal of Experimental Social Psychology, 33, 276-295. doi:10.1006/jesp.1996.1321

Sanbonmatsu, D. M., Vanous, S., Hook, C., Posavac, S. S., \& Kardes, F. R. (2011). Whither the alternatives: Determinants and consequences of selective versus comparative judgemental processing. Thinking \& Reasoning, 17, 367-386. doi:10.1080/13546783.2011.625659

Savitsky, K., Van Boven, L., Epley, N., \& Wight, W. M. (2005). The unpacking effect in allocations of responsibility for group tasks. Journal of Experimental Social Psychology, 41, 447-457. doi:10.1016/j.jesp.2004.08.008

Sloman, S. A. (1996). The empirical case for two systems of reasoning. Psychological Bulletin, 119, 3-22.

Sloman, S., Rottenstreich, Y., Wisniewski, E., Hadjichristidis, C., \& Fox, C. R. (2004). Typical versus atypical unpacking and superadditive probability judgment. Journal of Experimental Psychology: Learning, Memory, and Cognition, 30, 573-582. doi:10.1037/0278-7393.30.3.573

Smith, A. R., \& Price, P. C. (2010). Sample size bias in the estimation of means. Psychonomic Bulletin \& Review, 17, 499-503. doi:10.3758/PBR.17.4.499

Sprenger, A., \& Dougherty, M. R. (2006). Differences between probability and frequency judgments: The role of individual differences in working memory capacity. Organizational Behavior and Human Decision Processes, 99, 202-211. doi:10.1016/j.obhdp.2005.08.002 
Sprenger, A. M., Dougherty, M. R., Atkins, S. M., Franco-Watkins, A. M., Thomas, R. P., Lange, N., \& Abbs, B. (2011). Implications of cognitive load for hypothesis generation and probability judgment. Frontiers in Cognitive Science, 2(129), 1-15. doi: 10.3389/fpsyg.2011.00129

Stanovich, K. E., \& West, R. F. (2000). Individual differences in reasoning: Implications for the rationality debate? Behavioral and Brain Sciences, 23(5), 645-665. doi:10.1017/S0140525X00003435

Suls, J., Chambers, J., Krizan, Z., Mortensen, C. R., Koestner, B., \& Bruchmann, K. (2010). Testing four explanations for the better/worse-than-average effect: Single- and multiitem entities as comparison targets and referents. Organizational Behavior and Human Decision Processes, 113, 62-72. doi:10.1016/j.obhdp.2010.03.003

Taylor, S. E., \& Brown, J. D. (1988). Illusion and well-being: A social psychological perspective on mental health. Psychological Bulletin, 103, 193-210.

Teigen, K. H. (1974). Overestimation of subjective probabilities. Scandinavian Journal of Psychology, 15, 56-62. doi:10.1111/j.1467-9450.1974.tb00556.x

Teigen, K. H. (1983). Studies in subjective probability: III. The unimportance of alternatives. Scandinavian Journal of Psychology, 24, 97-105. doi:10.1111/j.14679450.1983.tb00481.x

Teigen, K., \& Brun, W. (2011). Responsibility is divisible by two, but not by three or four: Judgments of responsibility in dyads and groups. Social Cognition, 29, 15-42. doi:10.1521/soco.2011.29.1.15

Tversky, A., \& Koehler, D. J. (1994). Support theory: A nonextensional representation of subjective probability. Psychological Review, 101, 547-567.

Weinstein, N. D. (1980). Unrealistic optimism about future life events. Journal of Personality and Social Psychology, 39, 806-820. 
Windschitl, P. D. (2000). The binary additivity of subjective probability does not indicate the binary complementarity of perceived certainty. Organizational Behavior and Human Decision Processes, 81, 195-225.

Windschitl, P. D. (2002). Judging the accuracy of a likelihood judgment: The case of smoking risk. Journal of Behavioral Decision Making, 15, 19-35.

Windschitl, P. D., Conybeare, D., \& Krizan, Z. (2008). Direct-comparison judgments: When and why above- and below-average effects reverse. Journal of Experimental Psychology: General, 137, 182-200. doi:10.1037/0096-3445.137.1.182

Windschitl, P. D., Kruger, J., \& Simms, E. N. (2003). The influence of egocentrism and focalism on people's optimism in competitions: When what affects us equally affects me more. Journal of Personality and Social Psychology, 85, 389-408.

Windschitl, P. D., Rose, J. P., Stalkfleet, M. T., \& Smith, A. R. (2008). Are people excessive or judicious in their egocentrism? A modeling approach to understanding bias and accuracy in people's optimism. Journal of Personality and Social Psychology, 95, 253-273. doi:10.1037/0022-3514.95.2.253

Wissler, R. L., Kuehn, P. F., \& Saks, M. J. (2000). Instructing jurors on general damages in personal injury cases: Problems and possibilities. Psychology, Public Policy, And Law, 6, 712-742. doi:10.1037/1076-8971.6.3.712

Yamagishi, K. (2002). Proximity, compatibility, and noncomplementarity in subjective probability. Organizational Behavior and Human Decision Processes, 87, 136-155. doi:10.1006/obhd.2001.2959 


\section{Appendix}

Items used in Experiments 1 and 2.

\begin{tabular}{|c|c|c|}
\hline Domain & Strong Sets & Weak Sets \\
\hline Movies & $\begin{array}{l}\text { The Godfather } \\
\text { The Shawshank Redemption } \\
\text { Schindler's List } \\
\text { Star Wars } \\
\text { Gladiator } \\
\text { Million Dollar Baby } \\
\text { Raiders of the Lost Ark } \\
\text { Pulp Fiction } \\
\text { The Lord of the Rings: The Return of the } \\
\text { King } \\
\text { Casablanca }\end{array}$ & $\begin{array}{l}\text { Cheaper by the Dozen } \\
\text { Spice World } \\
\text { Crossroads } \\
\text { Final Destination } \\
\text { Gigli } \\
\text { Rollerball } \\
\text { Son of the Mask } \\
\text { You Got Served } \\
\text { Date Movie } \\
\text { Glitter }\end{array}$ \\
\hline Foods & $\begin{array}{l}\text { Hardee's 1/3 Lb. Thickburger } \\
\text { McDonald's Sausage McMuffin } \\
\text { Burger King French Fries (large) } \\
\text { McDonald's Big Mac } \\
\text { KFC Original Chicken Breast } \\
\text { Krispy Kreme Glazed Doughnut } \\
\text { Burger King French Toast Sticks } \\
\text { Pizza Hut Personal Pan Pepperoni Pizza } \\
\text { Taco Bell Beef Burrito } \\
\text { Perkins Blueberry Mammoth Muffin }\end{array}$ & $\begin{array}{l}\text { Broccoli } \\
\text { Cooked Wild Rice } \\
\text { a Panera Bread Plain Bagel } \\
\text { a Whole Cucumber } \\
\text { a Medium Peach } \\
\text { a Medium Apple } \\
\text { Dannon Non-Fat Vanilla Yogurt } \\
\text { a Medium Red Tomato } \\
\text { Silken Firm Tofu } \\
\text { a Banana }\end{array}$ \\
\hline States & $\begin{array}{l}\text { Pennsylvania } \\
\text { Texas } \\
\text { Georgia } \\
\text { New Jersey } \\
\text { Florida } \\
\text { Illinois } \\
\text { Ohio } \\
\text { Michigan } \\
\text { New York } \\
\text { Massachusetts }\end{array}$ & $\begin{array}{l}\text { Hawaii } \\
\text { South Dakota } \\
\text { Delaware } \\
\text { Nebraska } \\
\text { Montana } \\
\text { Nevada } \\
\text { Rhode Island } \\
\text { Vermont } \\
\text { New Mexico } \\
\text { Alaska }\end{array}$ \\
\hline Surnames & $\begin{array}{l}\text { Miller } \\
\text { Taylor } \\
\text { Brown } \\
\text { Moore } \\
\text { Jones } \\
\text { Thomas } \\
\text { Wilson } \\
\text { Davis } \\
\text { Harris } \\
\text { Williams }\end{array}$ & $\begin{array}{l}\text { Beckerman } \\
\text { Leach } \\
\text { Eichberg } \\
\text { Gibbs } \\
\text { Fonner } \\
\text { Humphries } \\
\text { Pennington } \\
\text { Dallmier } \\
\text { Osmon } \\
\text { Rhoe }\end{array}$ \\
\hline
\end{tabular}




\section{Footnotes}

1. It is important to note that our conceptual claims about aggregation in probability judgments involve judgments in which the target event is a singleton rather than a compound event. This is a common form of probability judgment and is a primary focus of research (e.g., Tversky \& Koehler, 1994). One could devise other, less common versions of probability judgments, for which our conceptual assumptions would need modification. If, for example, we changed the form of our probability judgments to this form: 'What is the probability that any one of four movies, from the set of ten, had the highest evaluation?' then an aggregation would be required both for the four target events and the six alternative events. Or if we asked, 'What is the probability that this movie would be one of the top five movies among the list of ten', then, again, different aggregation processes would be applicable. Relatedly, we could have devised unusual versions of comparative questions for which different processed would be involved (e.g., 'How high do you think the evaluation of this movie was compared to the best of all the other movies?'). However, these unusual formulations of comparative and probability questions are not what are used to capture and study the biases that we aimed to address and organize, so we don't use those formulations here. In short, we used the most common (and commonly tested) forms of both probability judgments and comparative judgments in our research.

2. For the pre-task, half the participants were asked to categorize household items, which was a task designed as an entirely irrelevant task (i.e., a control task). The other half of the participants gave ratings of the evidence for stimulus items (e.g., they rated the population of Michigan using 5-point scale from Very Unpopulated to Very Populated). Overall, they made ratings about 20 items in each of the four item categories; 10 of the items were ones about which they later made comparative or probability judgments. It was thought that the 
apparent relative strength and weakness of items would be accentuated for participants who did these ratings in the pre-task. However, the type of pre-task did not significantly impact any of the main results from the study.

3. In the no delay condition, the focal item was immediately in red font. In the delay condition, the focal item's font turned red after 8,10 , or 12 seconds, for the set sizes of 2 , 5, and 10, respectively. During that delay, a prompt encouraged participants to think about the items vis-à-vis the relevant dimension (e.g., 'Please think about how highly rated these movies were by the general public'). Previous work has shown that the presence vs. absence of a delay when the focal item is denoted after all items are presented can influence the magnitude and sometimes even the direction of a non-selective superiority bias (Windschitl, Conybeare, \& Krizan, 2008). However, this factor had no significant impact on any of the main results from the current study.

4. In both studies, participants made absolute estimates of the individual stimuli. For example, when making judgments about individual movies, participants were asked to indicate what rating they thought each movie was given on a popular web site on a scale from 1 to 10 . These judgments were presented in a random order for each participant. Because these responses were not instrumental in testing the predictions of RSJF and always occurred after making the referent-specific judgments, we do not report the results in this manuscript. 
Table 1. Questions used in Studies 1 and 2.

\begin{tabular}{|c|c|c|}
\hline \multirow{2}{*}{ Domain } & \multicolumn{2}{|c|}{ Judgment Type } \\
\hline & Probability & Comparative \\
\hline Movies & $\begin{array}{l}\text { Of all the movies listed on the screen, what } \\
\text { is the probability that the movie [MOVIE } \\
\text { TITLE] had the highest rating/evaluation } \\
\text { (i.e., highest from this list)? }\end{array}$ & $\begin{array}{l}\text { How high was the rating/evaluation of the } \\
\text { movie [MOVIE TITLE] compared to the } \\
\text { ratings of the other movie(s) listed on the } \\
\text { screen? }\end{array}$ \\
\hline Foods & $\begin{array}{l}\text { Of all the foods listed on the screen, what is } \\
\text { the probability that [FOOD] has the highest } \\
\text { rate of calories-per-serving (i.e., highest } \\
\text { from this list)? }\end{array}$ & $\begin{array}{l}\text { How high is the rate of calories-per-serving } \\
\text { for [FOOD] compared to the other food(s) } \\
\text { listed on the screen? }\end{array}$ \\
\hline States & $\begin{array}{l}\text { Imagine that we had a computerized list of } \\
\text { the names of all the people living in the } \\
\text { states mentioned above. From this list of } \\
\text { names, we randomly selected } 1 \text { person. } \\
\text { What is the probability that this person } \\
\text { would be living in [STATE]? }\end{array}$ & $\begin{array}{l}\text { In terms of population size, how big is } \\
\text { [STATE] compared to the other state(s) } \\
\text { listed on the screen? }\end{array}$ \\
\hline Surnames & $\begin{array}{l}\text { Assume that we have a computerized list of } \\
\text { the last names of all the people living in } \\
\text { Johnson County (IA) who have one of the } \\
\text { last names listed above. From this list of } \\
\text { people, we randomly select } 1 \text { person. What } \\
\text { is the probability that the person's last name } \\
\text { will be [SURNAME]? }\end{array}$ & $\begin{array}{l}\text { In Johnson County (IA), how common (i.e., } \\
\text { frequent) is [SURNAME] compared to the } \\
\text { other name(s) listed on the screen? }\end{array}$ \\
\hline
\end{tabular}




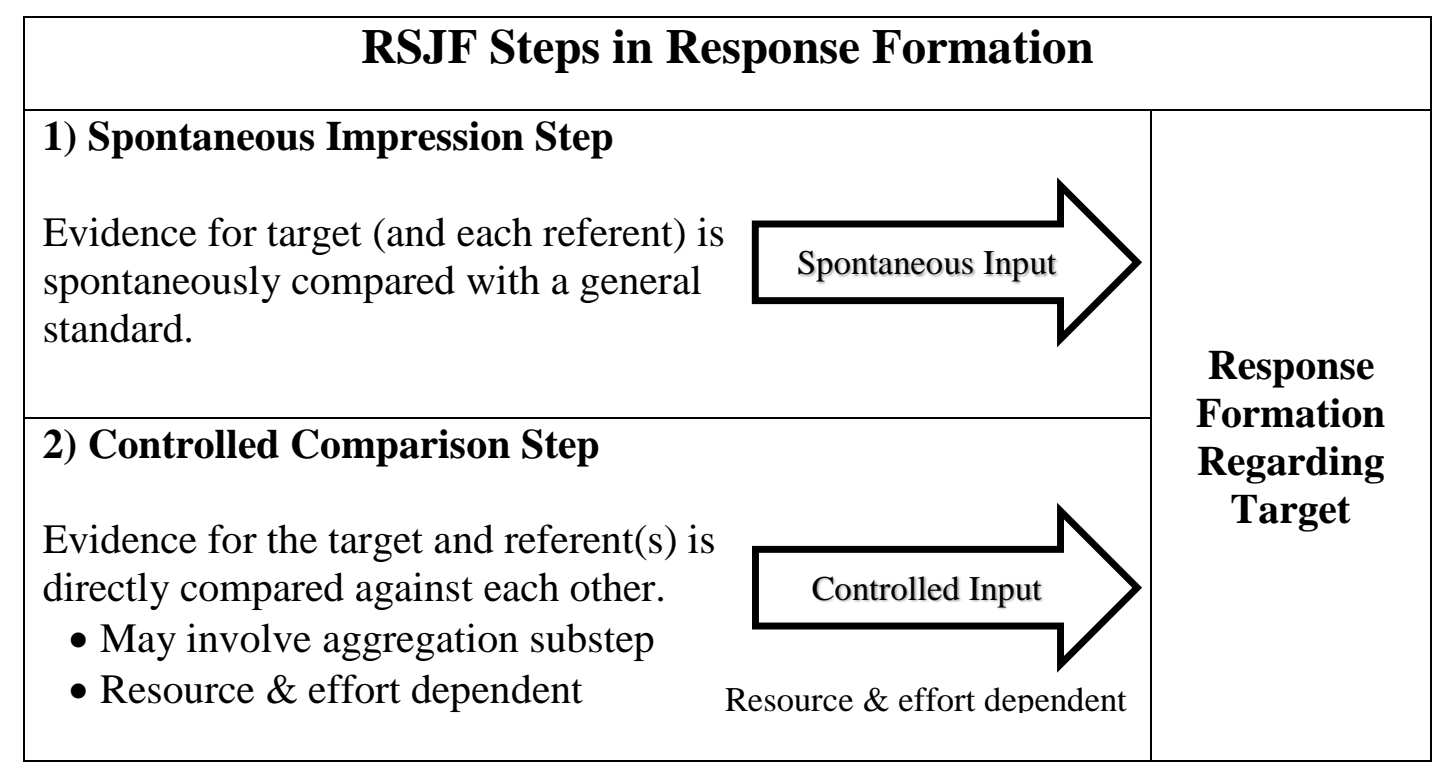

Figure 1. Visual depiction of the Referent-Specific Judgment Framework. 

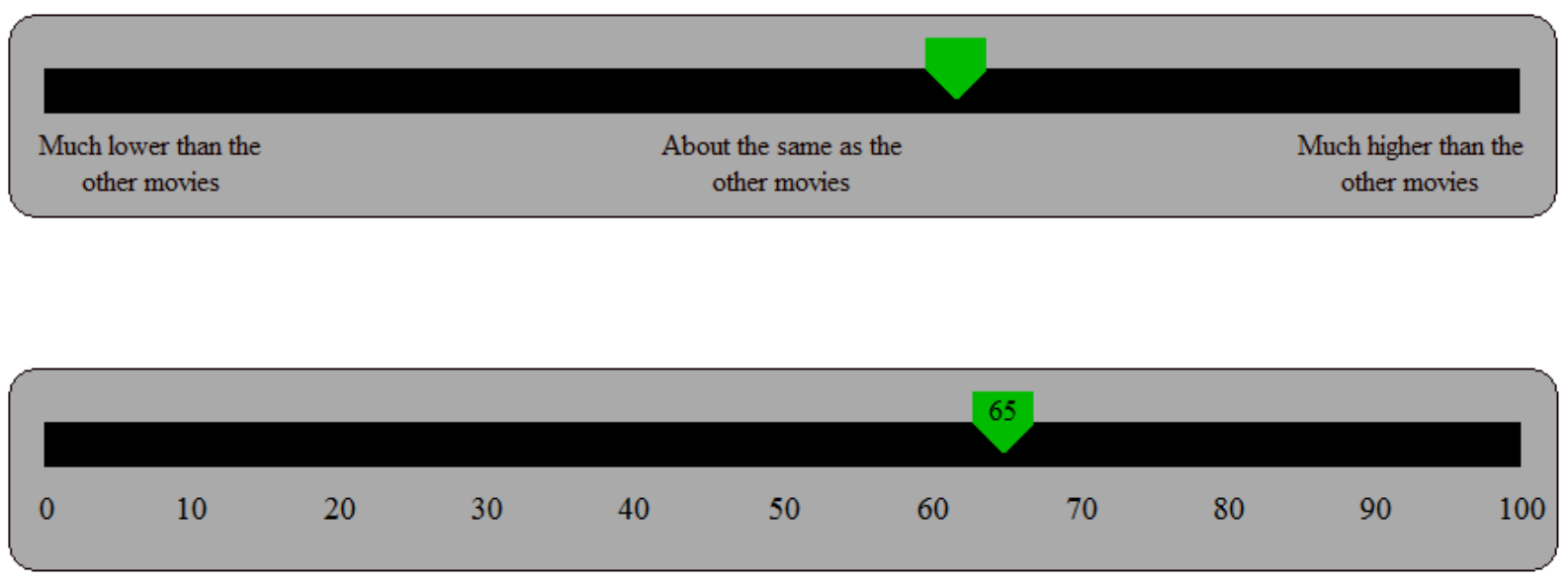

Figure 2. Examples of scales used for comparative (top) and probability (bottom) judgments for the food domain. 


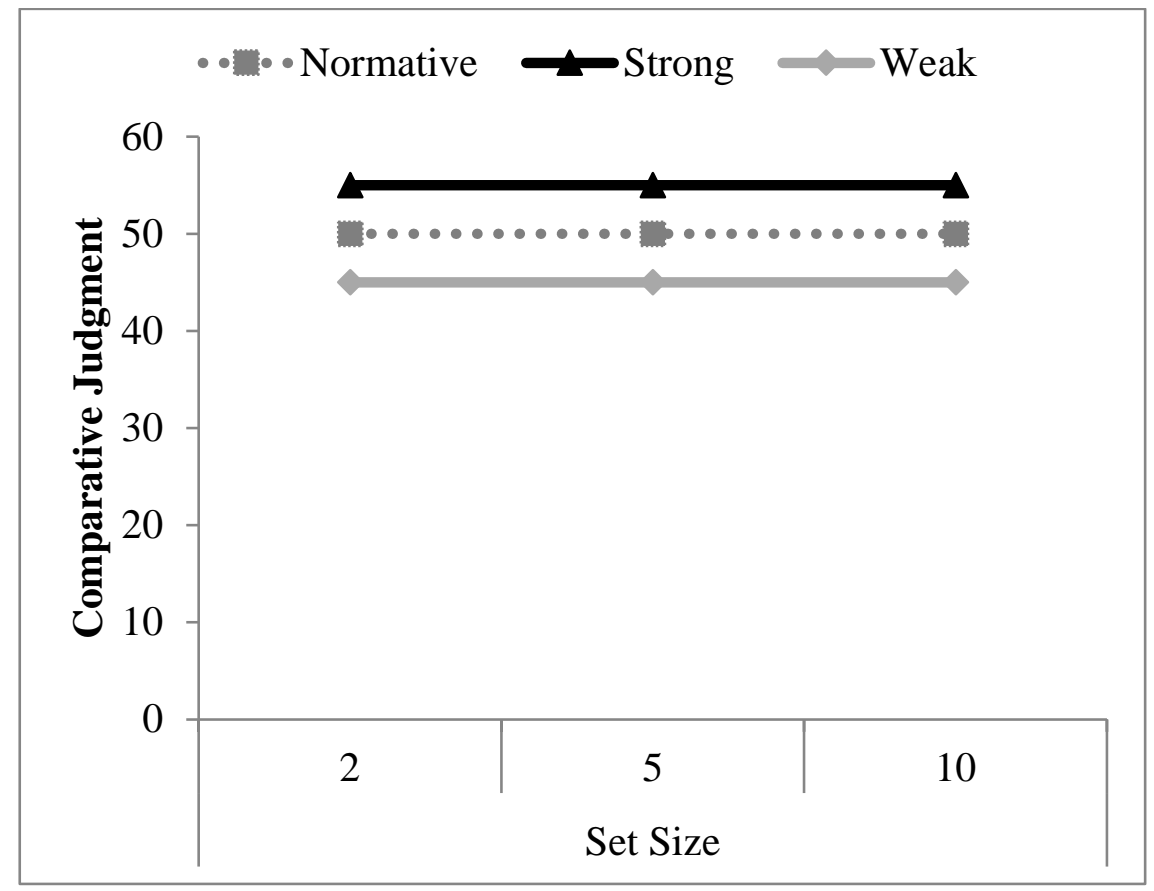

Figure 3. The solid lines are predictions for comparative judgments about targets from strong and weak sets in Study 1. The dotted line displays the normative standard. 


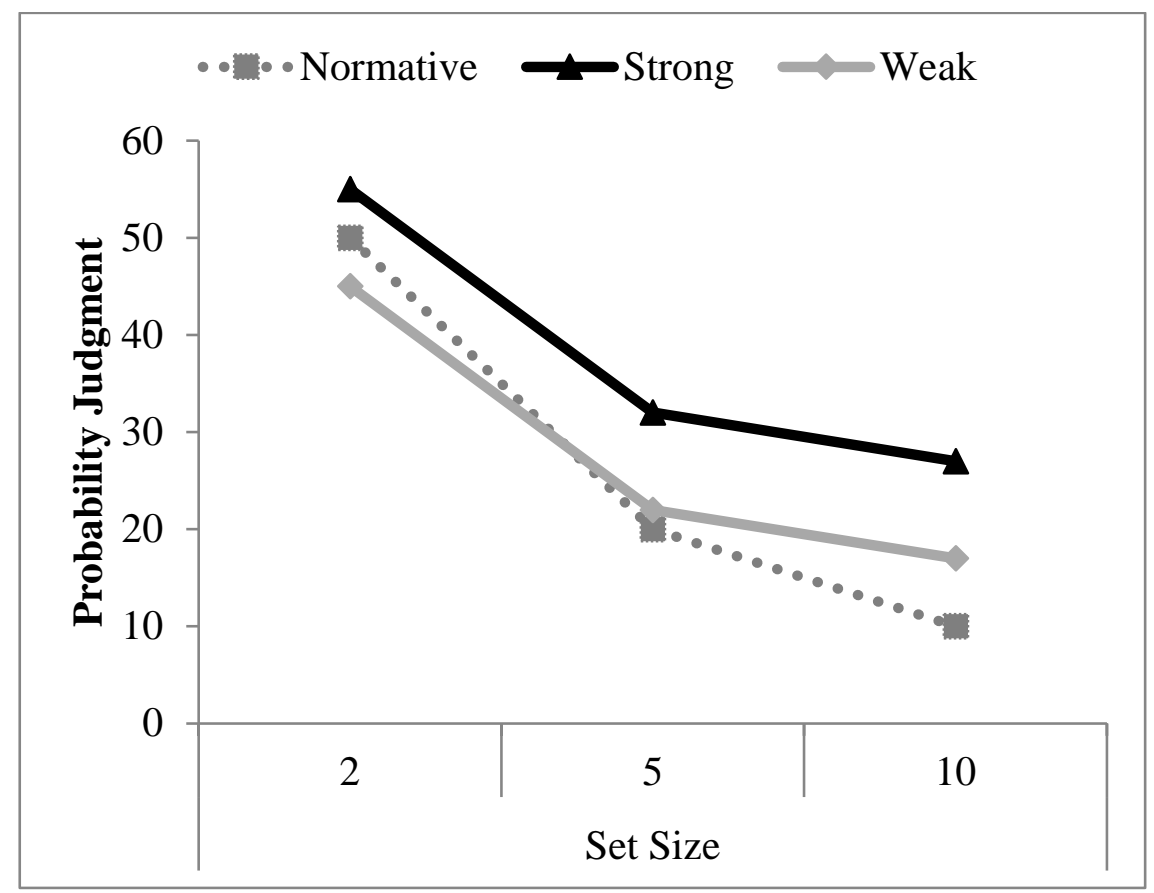

Figure 4. The solid lines are predictions for the probability judgments about targets from strong and weak sets in Study 1. The dotted line displays the normative standard. 


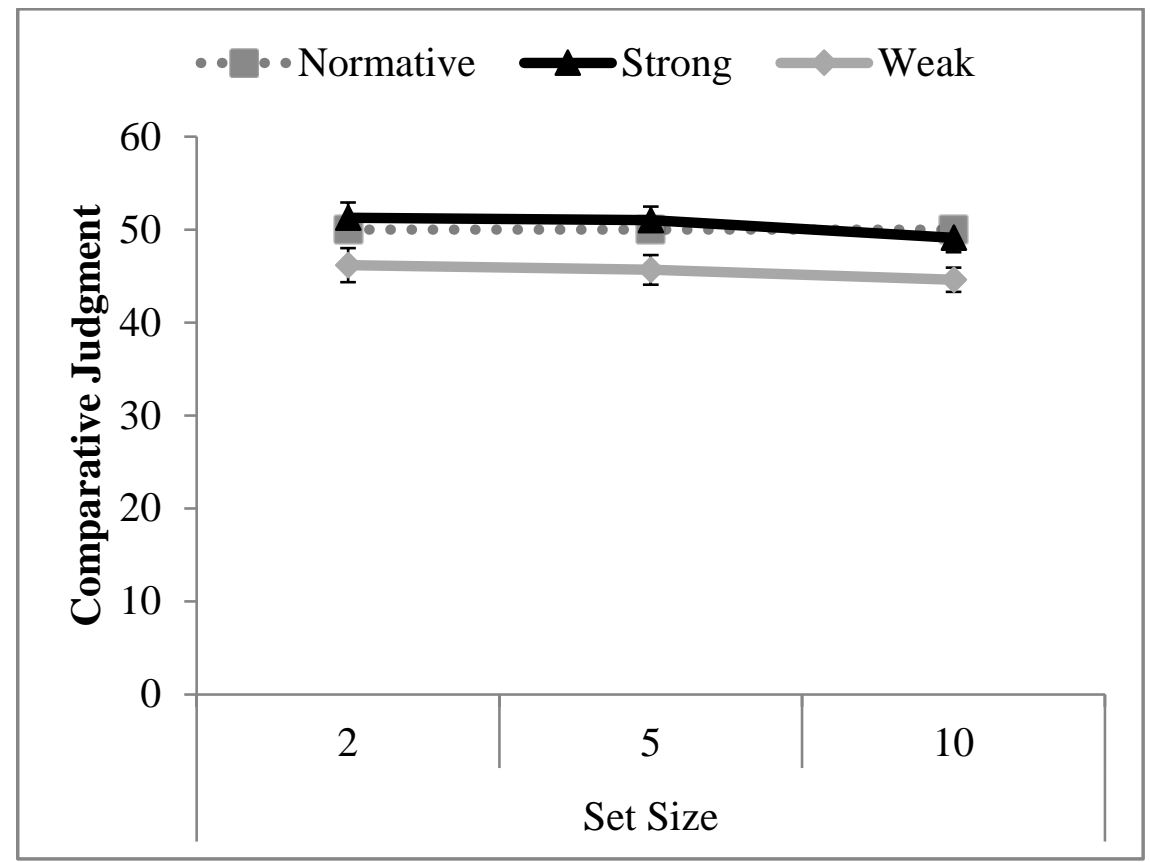

Figure 5. Participants' average comparative judgments as a function of set size and set strength for Study 1. Error bars represent \pm 1 SE. 


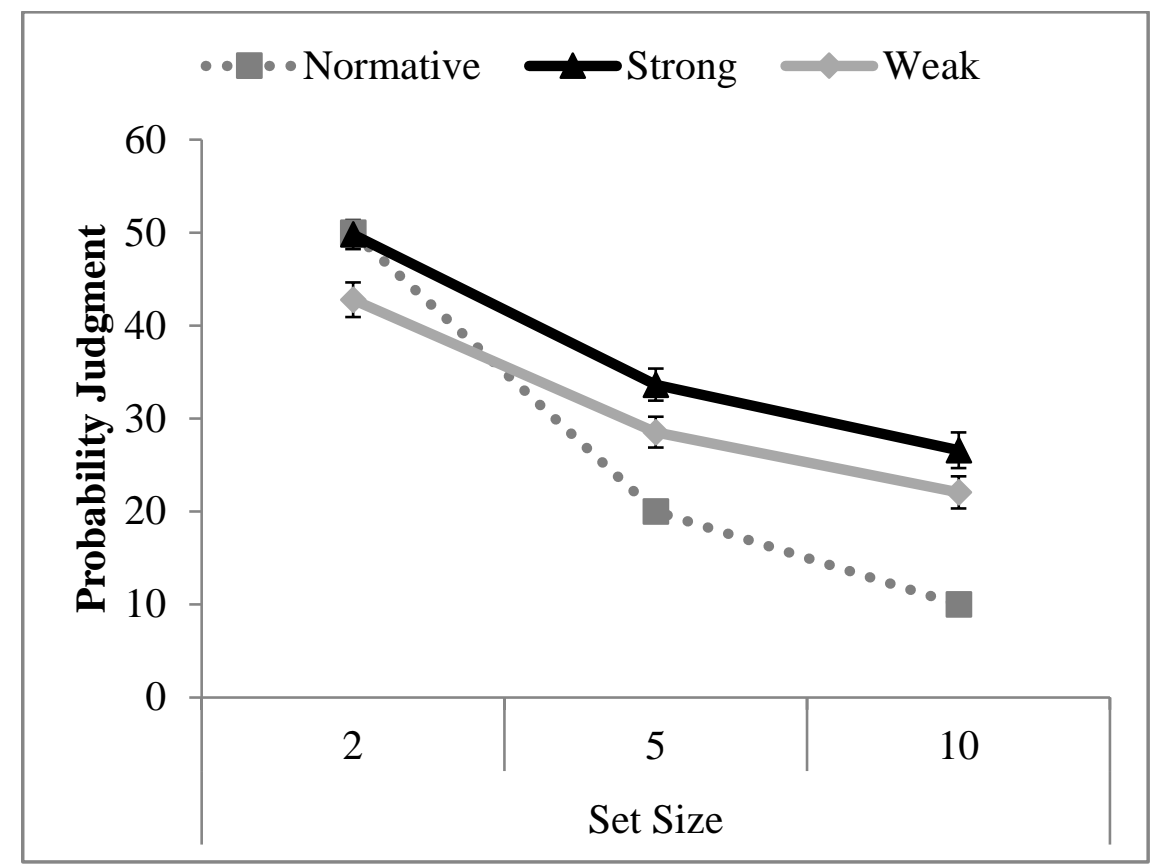

Figure 6. Participants' average probability judgments as a function of set size and set strength for Study 1. Error bars represent \pm 1 SE. 


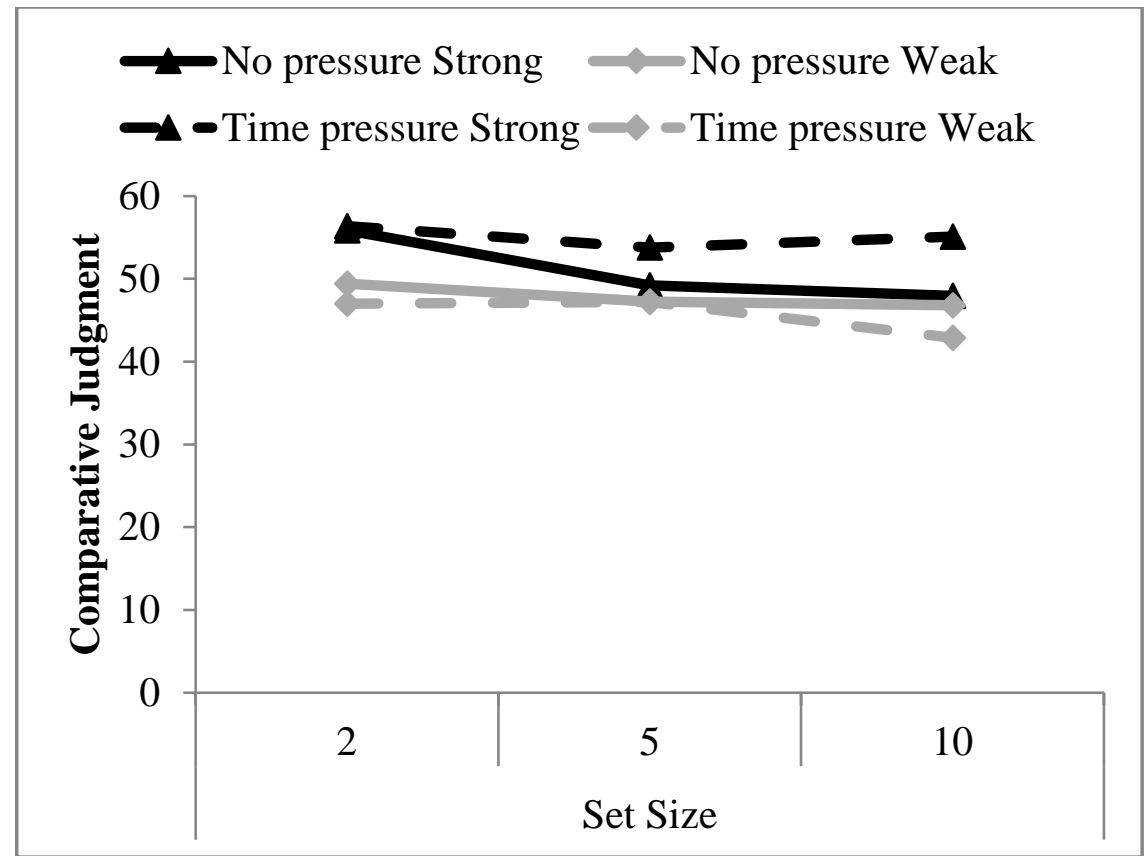

Figure 7. Participants' average comparative judgments as a function of time pressure, set size, and set strength for Study 2. 


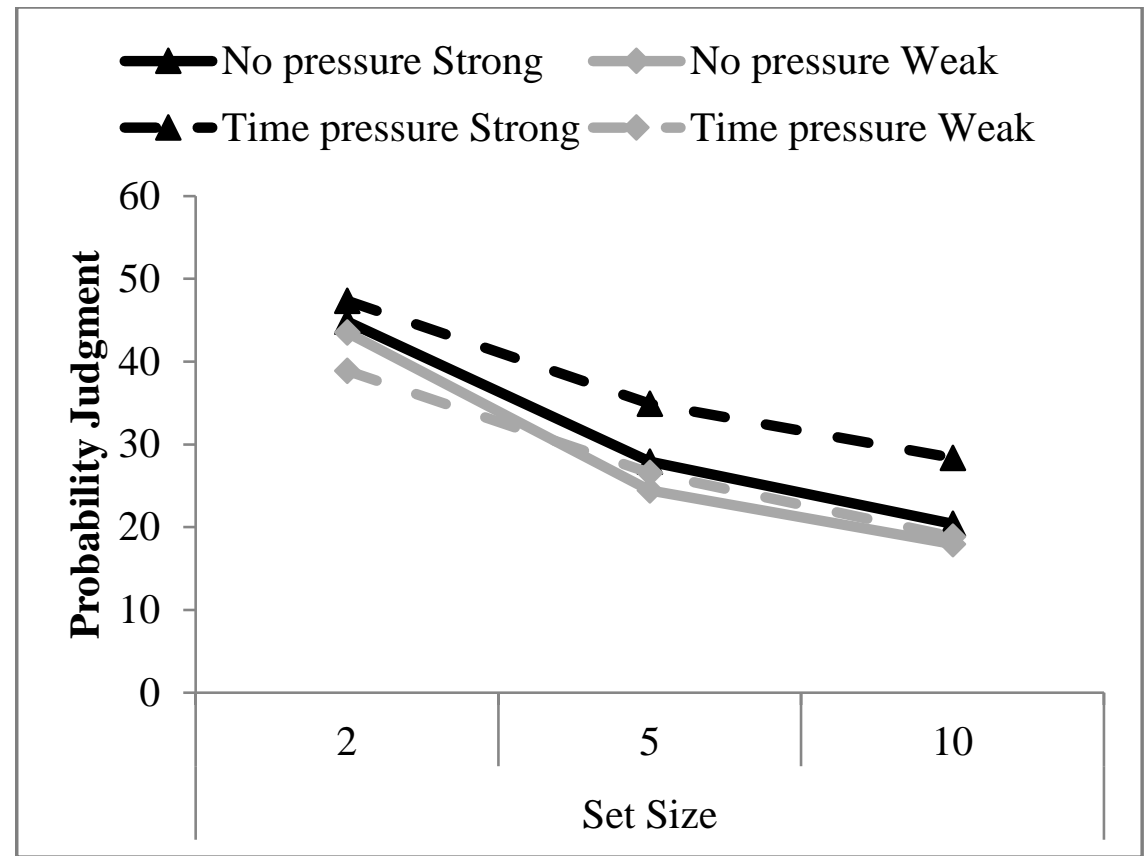

Figure 8. Participants' average probability judgments as a function of time pressure, set size, and set strength for Study 2. 